\title{
Cystic disease of the liver and biliary tract
}

\author{
A Forbes, I M Murray-Lyon
}

\begin{abstract}
The widespread availability of ultrasound imaging has led to more frequent recognition of cystic disease affecting the liver and biliary tract. There is a wide range of possible causes. Cystic disease of infective origin is usually caused by an Echinococcal species, or as the sequel of a treated amoebic or pyogenic abscess. The clinical and radiological features are often then distinctive and will not be dwelt upon in this review, except in respect of their contribution to the differential diagnosis of non-infective disorders. The principal noninfective cysts can be conveniently divided between the simple cyst, the polycystic syndromes (usually with coexistent renal disease), Caroli's syndrome, and choledochal cysts. The overlap between constituent members of these groups, and the association of cystic disease with hepatic fibrosis (especially with congenital hepatic fibrosis) has attracted considerable attention, and it has been suggested that they may all be considered to belong to a hepatobiliary fibrocystic continuum. In addition there are a variety of cystic neoplasms and a miscellany of unusual forms.
\end{abstract}

\section{Investigation and diagnosis}

Large cystic lesions may be recognised clinically, but in most cases will be found at ultrasound examination undertaken because of symptoms, or laboratory screening tests suggestive of hepatobiliary disease; cysts are not infrequently an incidental finding when scans are done for unrelated clinical problems.

An accurate differential diagnosis will often be possible from ultrasonography alone. ${ }^{12}$ Most commonly, one or more clearly defined echolucent spaces are identified within the liver substance. When these have thin walls and reduce the signal from more distant structures, the most likely diagnosis is of simple cyst and further investigation is usually unnecessary. It is suggested, however, that magnetic resonance (MR) imaging may be particularly helpful in doubtful cases. ${ }^{34}$ Thicker walled single or multiple cysts with a multilayer or laminated margin are likely to be hydatid, and the presence of daughter cysts within the lesion is virtually pathognomonic. A supportive history and positive serology will usually allow confirmation of this diagnosis. Aspiration of presumptive hydatid cysts is contra-indicated because of the perceived high risk of anaphylaxis if cyst contents spill into the peritoneum, and there is usually no need to consider aspiration if hydatid disease is suspected. The hazard has perhaps been over emphasised, however, and if hydatid disease is unlikely and cysts have inconclusive sonographic appear- ances, aspiration for microbiological and cytological examination is warranted. Several reports - (for example, ${ }^{5}$ and our own unpublished observations) of needle diagnosis of unsuspected hydatid disease, and even therapy by ultrasound guided transcutaneous injection of sclerosant, ${ }^{67}$ indicate that if the transhepatic route is taken the risk of morbidity is low.

Distinction of abscess from cyst is relatively simple if an abscess has viscous echo dense contents with a thick wall and densely compressed surrounding hepatic parenchyma. Percutaneous aspiration allows confirmation of the diagnosis, provides material for microbiological examination, and may be of major therapeutic benefit. Positive blood cultures or amoebic serology may, however, render aspiration superfluous, given that small single abscesses can be effectively managed with systemic antimicrobials alone. Open surgical drainage remains necessary for optimal results in some patients with chronic multiloculated abscesses.

Cystic lesions in continuity with the biliary tree or with vascular structures may be identified by ultrasound (the latter particularly so with Doppler probes), but it will usually be necessary to obtain contrast studies (by ERCP or angiography) for complete diagnosis. In this context computed tomography and MR images of the hepatobiliary region do not appear at present to offer many advantages over high resolution sonographic examination. The interested reader is referred to one of a number of illustrated reviews in the radiological literature. ${ }^{1248}$

Liver biopsy tends to be avoided in the investigation of cystic disorders, a stance certainly justified when there is suspicion of hydatid disease, and probably so when imaging suggests choledochal cyst, but the recognition of underlying fibrosis is then less likely, and the clinician is denied potentially important prognostic information.

\section{SIMPLE HEPATIC CYSTS}

Benign non-parasitic cysts of the liver, once considered rare because they are generally small and asymptomatic, are more commonly shown by modern imaging (prevalence between $0 \cdot 1^{9}$ and $2 \cdot 5 \%),{ }^{2}$ more so in women (female:male ratio $1 \cdot 5),{ }^{2}$ more often in the right lobe, and probably of congenital origin. The cysts are lined by biliary columnar epithelium, but it is relatively unusual for the fluid contents to be bile. If the typical appearances at sonography described above are seen, no further investigation or treatment is required. The sensitivity of aspiration cytology in potentially neoplastic cysts with no definite solid component is low, but may be improved by assay of cyst contents for tumour markers such as 
carcinoembryonic antigen. ${ }^{10}$ Other than from serial scans begun at the time of infection it is not clear that postinfective cysts - longterm sequelae of unaspirated abscesses - can accurately be distinguished from congenital benign cysts. ${ }^{18}$

All benign cysts appear subject to a variety of complications. Bleeding into or infection of the cyst contents may be responsible for the onset of pain or other symptoms; enlargement of cysts also occurs without obvious cause, and may then lead to the presence of a painful swelling, ${ }^{11}$ obstructive jaundice ${ }^{12}$ or intraperitoneal perforation. ${ }^{13}$ Although surgical intervention may become necessary, in the absence of peritonitis or severe intraabdominal bleeding, conservative management is probably to be preferred, ${ }^{14} 15$ with $^{12}$ or without ${ }^{16}$ percutaneous aspiration. Recurrent symptoms may be prevented by internal drainage of the cyst ${ }^{17}$ or by the instillation of sclerosant, ${ }^{18}{ }^{19}$ the latter course in our view to be followed only after very careful direct cholangiography has excluded communication with the biliary tree, if biliary sclerosis is to be avoided. Although there does not seem to be a major problem with alcohol injection in analogous management of hydatid cysts ${ }^{7}$ longterm follow up data are sparse. Surgical deroofing of cysts without drainage of the residual cavity is strongly recommended ${ }^{20}$ if surgery is thought indicated.

Concern that simple cysts represent a premalignant state has been generated by a series of reports of neoplasia in apparently preexisting benign cysts. The tumours are, however, of disparate histological type - for example, mucoepidermoid carcinoma, ${ }^{21}$ multifocal papillary cystadenocarcinoma, ${ }^{22}$ squamous cell carcinoma $^{23}$ - and these may represent coincidental associations rather than complications. The observation that foci of cystadenoma and cystadenocarcinoma (the most common malignancy described with simple cysts) coexisted with hamartomatous bile ducts ${ }^{24}$ tends, however, to support the view ${ }^{22}$ that there is a causative link. Although these tumours appear to have a generally poor prognosis, their rarity does not seem to us to warrant indefinite surveillance of asymptomatic patients believed to have simple cysts alone. The claimed stronger association between non-parasitic liver cysts and benign liver tumours ${ }^{25}$ is, at first sight, more convincing, but probably reflects rather the association between von Meyenburg complexes, hepatic fibrosis and polycystic disease (see below).

\section{POLYCYSTIC DISEASES}

Adult polycystic disease, of autosomal dominant inheritance with high penetrance, may present at any age with renal manifestations, but although hepatic involvement is common, clinically significant liver disease is rare $(<15 \%)$, and does not usually affect the natural history.$^{26}$ Hepatic cysts are not often seen before puberty but become more frequent with increasing age $(<20 \%$ in those under $30,,^{27},>75 \%$ in those over $70^{26} 27$ ); they are more common in women, ${ }^{28}$ especially those with children. When liver disease occurs it usually accompanies relatively advanced renal disease (mean creatinine clearance two thirds of those without hepatic cysts. ${ }^{28}$ ) Polycystic liver disease may, however, occur in the absence of significant renal involvement. The cysts are lined by biliary type epithelium which retains a functional response to secretin. ${ }^{29}$ Their pathogenesis (akin to that of simple cysts) is considered to reflect failed involution of excess intralobular bile ducts during embryological development. ${ }^{3031}$ Liver biopsy shows portal tract fibrosis and numerous cystically dilated channels; the hepatic parenchyma is otherwise normal but it is not unusual to find Von Meyenburg complexes in non-cystic parts of the liver (see below). Overt congenital hepatic fibrosis (see below) certainly occurs $^{32}$ but is unusual.

Apparently spontaneous infection of hepatic cysts is described, usually with gut derived organisms, and prompt recognition and drainage greatly reduces the mortality which may exceed $75 \%$ with antibiotic therapy alone. ${ }^{33}$ Mechanical cholestasis caused by the cysts is rare, ${ }^{31}$ but a common topic of case reports: it remains unclear why the pressure within the cysts should rise sufficiently to cause obstruction, but hormonal responsiveness ${ }^{29}$ may be of relevance. Relief of biliary obstruction may be satisfactorily provided by percutaneous aspiration. ${ }^{31}$ In advanced disease portal hypertension responsible for ascites and variceal haemorrhage can become problematic ${ }^{34}$ : good results may be obtained from portosystemic anastomosis. In the majority of cases, however, management will be that of chronic renal failure with consideration of renal transplantation. If there are problems related to the sheer size of the liver or coexistent symptomatic portal hypertension, then many units will now take the opportunity to carry out double organ grafts from the same donor: good results are reported, but disappointingly King's was not the first unit to publish specifically on this topic. ${ }^{35}$

The autosomal recessive form of polycystic disease usually presents in infancy with renal failure and massive kidneys: these patients rarely have significant liver disease. Presentations later in life are associated with less aggressive renal disease, but with a progressively higher frequency of congenital hepatic fibrosis and likelihood of portal hypertension. ${ }^{32}$ Patients with the mildest renal involvement are perhaps most likely to have an hepatic presentation. The clinical diagnosis based on renal enlargement and hepatomegaly is supported by biochemical evidence of renal failure, relatively normal liver function, and the demonstration of renal cysts on utrasound scanning: the hepatic cysts are often too small to be identified sonographically. Histologically, the hepatic cysts appear identical to those of autosomal dominant cases.

Liver Unit authors were responsible for the recognition of a number of other renal cystic disorders associated with hepatic fibrosis, ${ }^{36}$ the latter apparently indistinguishable from congenital hepatic fibrosis.

\section{CONGENITAL HEPATIC FIBROSIS}

Congenital hepatic fibrosis deserves its present inclusion because of the frequency with which it is associated with cystic disease. In its overt form it usually presents in childhood with complica- 
tions of non-cirrhotic portal hypertension (especially bleeding), but may present in adulthood $;^{37}$ asymptomatic forms are encountered at all ages. It is most often associated with the recessive form of polycystic kidney disease, but at least two groups ${ }^{32}{ }^{38}$ give convincing accounts of an association between congenital hepatic fibrosis and autosomal dominant polycystic disease. Equally, in a few cases the kidneys are apparently normal. ${ }^{36}$ Histologically there is a considerable increase in fibrous stroma distributed in broad bands throughout the liver with focal epithelial components and islands of normal lobular architure. Such 'pure' congenital hepatic fibrosis may be disguised by coexistent histological features of polycystic disease, and often by the presence of Von Meyenburg complexes. These biliary microhamartomata lie within dense fibrous stroma and surround epithelially lined irregular spaces which may contain bile. The complexes expand within or adjacent to the portal tracts and, as they are usually multiple, may be confused with micrometastases. They may be responsible for portal hypertension without more generalised fibrosis.

The Liver Unit described the association of congenital hepatic fibrosis with intra and even extra hepatic biliary dilatation ${ }^{36}$ producing a picture identical to Caroli's syndrome except that in that situation there is no fibrosis of the congenital hepatic fibrosis pattern.

A recent autopsy study ${ }^{25}$ which supported the association of fibrosis with cystic disease added the new observation that benign hepatic adenomas are associated with non-parasitic cysts; that the description is of polycystic disease rather than of simple cysts seems likely, but the significance of the association is probably of greater importance than the semantics of diagnosis.

\section{CAROLI'S SYNDROME}

Congenital dilatation of the intrahepatic bile ducts without obstruction was recognised by Caroli in 1958. ${ }^{39}$ Pure Caroli's syndrome remains an unusual diagnosis, with fewer than 150 cases in the world literature. A hereditary component - possibly recessive autosomal transmission - is supported by a report of the condition in two sisters. ${ }^{40}$ The saccular cystic dilatations more commonly affect the left lobe, and may be associated with biliary stasis, cholangitis, stone formation (in about $25 \%$ ), and pain. Involvement of the extra hepatic bile ducts is unusual. Although symptoms may begin in childhood and progress remorselessly via fibrocholangiomatosis to cirrhosis, a significant proportion of affected individuals will remain asymptomatic. The diagnosis should be seriously considered in any child with cholangitis. The combination of ultrasonography and ERCP lead to the diagnosis, although there is a small risk that the latter may reprecipitate cholangitis. Management depends on correct diagnosis and on the extent of liver involvement. Symptomatic disease affecting only one lobe of the liver can usually be successfully resected, ${ }^{41}$ albeit with considerable difficulty if extensive intrahepatic cholelithiasis has to be dealt with concurrently. ${ }^{42}$ More extensive resection, with hepatojejunal anastomosis, is also possible for multilobular disease,,$^{434}$ and the option of orthotopic transplantation remains for the end-stage patient with bilobar disease and/or cirrhosis, so long as sepsis can be controlled preoperatively.

Caroli's syndrome may be complicated by pancreatitis, ${ }^{45}$ obstructive portal lymphadenopathy ${ }^{46}$ or extra biliary sepsis, ${ }^{47}$ and advanced disease is usually associated with fibrocholangiomatosis; itself often responsible for portal hypertension.

Primary sclerosing cholangitis has a number of common features with Caroli's syndrome, especially when dilated duct segments take on a cystic appearance. ${ }^{48}$ Although a firm diagnosis is usually possible there are occasions when the two conditions cannot be clearly distinguished, and it is possible that an overlap syndrome exists.

Caroli's syndrome is certainly associated with hepatic fibrosis, and a report of Caroli's syndrome in renal polycystic disease ${ }^{49}$ suggests again that the distinctions between the different cystic diagnoses are not fundamental but more a matter of degree. Also consistent with this notion, is the important observation that Caroli's syndrome is probably a premalignant condition; frank malignancy ${ }^{47}$ may be preceded by biliary epithelial dysplasia. $^{50}$

\section{CHOLEDOCHAL CYSTS}

Choledochal cysts account for approximately $1 \%$ of all benign biliary disease ${ }^{51}$ and as recently as 1980 less than $40 \%$ were diagnosed preoperatively. ${ }^{52}$ They are primarily of concern to paediatricians and paediatric surgeons as more than $60 \%$ present before 10 years of age. The frequency is highest in Japan but appears relatively uniform across the rest of the globe. Numerous large historical series have been reported, but this relatively common rarity has continued to exert an appeal to authors and editors alike, because several hundred papers can be identified from Index medicus over the past five years alone many of these being single case reports. A consensus on management is nevertheless emerging despite the absence of controlled trials. Almost all authorities now use modifications of the Alonso-Lej classification, ${ }^{53}$ typically dividing choledochal cysts into four groups (Fig 1). The commonest (type I) comprises a fusiform or saccular dilatation of the extrahepatic biliary tree with a normal or stenotic distal common bile duct. Less often cysts appear as common bile

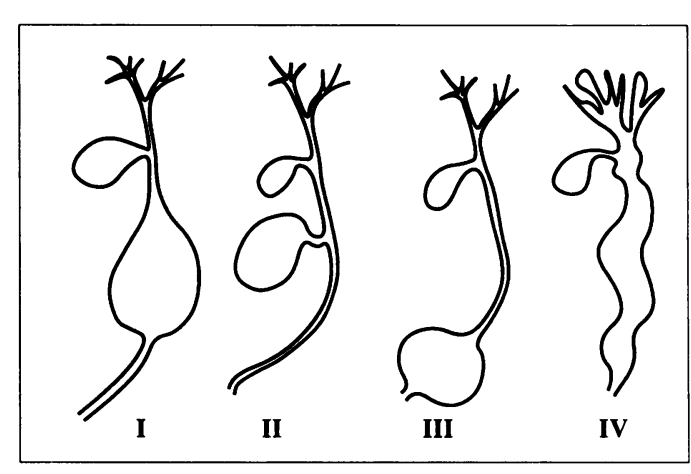

Figure 1: Classification of choledochal cysts (after Alonso-Lej et al. $)^{33}$ 


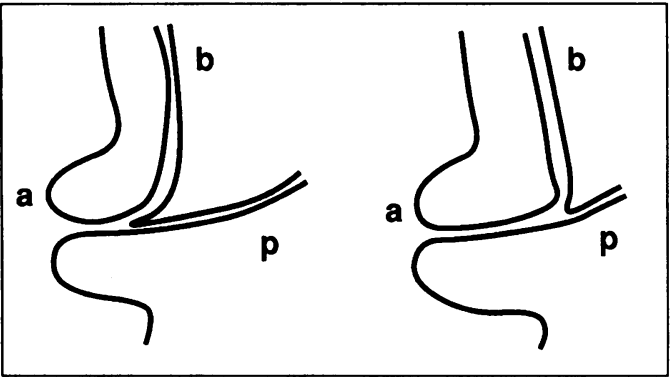

Figure 2: Illustration of long common pancreatobiliary channel. Left: typical junction of duct within sphincter zone. Right: long common channel with confluence of pancreatic and biliary systems proximal to sphincter. $a$-ampulla; $b$ - bile duct; $p$ - pancreatic duct.

duct diverticula (type II), are contained within the intraduodenal course of the duct (type III), or are more generalised, involving both intra and extrahepatic duct systems (type IV) (Fig 1). There is evidently a point at which it becomes difficult to distinguish between intrahepatic choledochal cyst and Caroli's syndrome; reports claiming heterogeneity of Caroli's syndrome ${ }^{54}$ apparently fail to appreciate the semantic nature of diagnosis in this situation. It is probably reasonable to consider choledochal cyst a part of the continuum already discussed in respect of the purely intrahepatic cystic conditions.

It is almost certain that choledochal cysts are of congenital origin, but the pathogenesis is less clear. It has been speculated that there is a differential abnormality in biliary epithelial proliferation in the embryo such that the solid core of proto-bile duct takes on a cystic form ${ }^{55}$; there is, however, no good evidence to support this. It is probable that reflux of pancreatic juice into the biliary tree is of relevance, however. ${ }^{56} \mathrm{~A}$ very large proportion of (and possibly all) patients with choledochal cyst have an unusually long common channel between the junction of the common bile duct and the main pancreatic duct and their joint outflow into the duodenum (Fig 2). ${ }^{57}$ The increased intraductal pressure associated with this anomaly predisposes to reflux and may also be associated with ectasia of the common channel ${ }^{57}$ (or indeed with pancreatitis. $)^{58}$ High concentrations of pancreatic enzymes within cyst fluid are common and pancreatitis may be diagnosed erroneously when hyperamylasaemia also occurs. ${ }^{59} \mathrm{~A}$ recent report of choledochal cyst in mother and daughter, both of whom had a long common channel and the same type of cyst $^{60}$ suggests that a hereditary element is important in some cases. Concurrent hepatic fibrosis has not attracted much attention, but certainly occurs, ${ }^{37}$ and lends support to the inclusion of choledochal cystic disease in the fibrocystic continuum.

Choledochal cysts may remain asymptomatic for many years (and possibly for life) but the majority will at some time cause one or more of the classical triad of pain, obstruction and palpable mass, often in association with cholangitis, or exhibit one of the less common features enumerated by the Department of Surgery at King's, ${ }^{61}$ such as ascites, variceal haemorrhage, or biliary peritonitis from spontaneous rupture.
Many patients will initially respond to simple medical measures, allowing time for careful assessment. Continued conservative therapy, provision of internal (or very occasionally external) drainage, or excision of the cyst must then be considered. The anatomy will usually be readily apparent from ultrasound scanning and ERCP, but will in a few cases remain enigmatic despite the full range of currently available radiological techniques. Treatment options should be considered in the light of the collected historical series. It appears that about $50 \%$ of patients having drainage procedures will need reoperation - usually because of recurrent sepsis or cholestasis, ${ }^{62}$ and one author ${ }^{63}$ makes the startling claim that his study 'provides conclusive evidence that any anastomosis of cyst wall to the gastrointestinal tract will ultimately result in stricture and cholangitis'. Moreover, at least one group ${ }^{64}$ have found (admittedly without taking full account of the technical considerations that determined the original operation), that the perioperative mortality is substantially higher for drainage procedures than for excision $(8 \cdot 6 \%$ $v 0 \%$ ). Excisions may vary between a cholecystectomy like removal of a type II cyst to a virtual extirpation of the biliary tree; most authors now prefer hepatojejunostomy. Excisions are not without their complications, however. One of the most experienced groups ${ }^{62}$ recently described a reoperation rate of nearly $10 \%$ in 73 excisions - although all seven ultimately did well. Major revisions were needed in most cases - usually conversion from hepatoduodenostomy to hepato-Roux-Y-jejunostomy after early haemorrhage/leak or late stenosis of the original anastomosis.

Carcinoma (adenocarcinoma in more than $90 \%$ ) is now well recognised as a complication of choledochal cysts. The life time risk for the individual may be as high as $50 \%$ if nonresectional surgery has been carried out. ${ }^{65}$ Bile stagnation, continual pancreatic reflux, and related chronic ulceration and regeneration of the cyst epithelium are thought causally relevant. ${ }^{66}$ Investigation of an 18 year old patient with a choledochal cyst showed an increase in secondary bile salts (most of which were unconjugated) within the cyst fluid, despite an entirely normal bile salt pattern in intrahepatic bile. The authors attribute this to bacterial colonisation within the cyst, and speculate that this caused the patient's biliary epithelial metaplasia and could contribute to the development of neoplasia ${ }^{67}$ It is probable that the cancer risk is substantially higher in patients presenting for the first time as adults, and attributed risks of between 5 and $40 \%$ have been suggested. ${ }^{66}$ Review of the computed tomography files in one Japanese institution ${ }^{68}$ revealed that eight of 35 consecutive adult cases of choledochal cyst had complicating malignancy. It must be noted that the studies with the longest follow up periods have consistently given the highest figures. Although the most common site of origin for malignant change is the posterior cyst wall, it is evident that there is a biliary 'field' defect as primary carcinoma may occur in biliary tissue uninvolved in the cyst, a striking $46 \%$ occurring in apparently normal gall bladder in one series. ${ }^{66}$ 
Prognosis once carcinoma has occurred is uniformly poor.

It is reasonable to conclude that choledochal cysts should always be excised with as complete resection of the (extrahepatic) biliary tree as possible. Such a policy should minimise postoperative cholangitis/cholestasis and achieve a low frequency of reoperation; it should also, with luck, eliminate the risk of malignant transformation within retained cystic components, or apparently normal more proximal biliary epithelium. When comprehensive excision implies a major pancreatic resection as well as dissection up into the liver, however, dogmatic views may have to be tempered, and especially so if the patient is asymptomatic!

\section{CYSTIC NEOPLASIA}

Hepatic cysts are not often neoplastic, but cystic tumours are recognised occasionally. Multilocular cystadenoma occurs almost exclusively in middle aged women who typically present with a rapidly growing upper abdominal mass; about one third develop clinical cholestasis. ${ }^{69}$ The distinction from simple cysts is straightforward histologically but less obvious clinically or radiologically: the presence of multiple cystic areas (usually several small lesions around a larger cyst), the presence of biliary obstruction, and the rate of progression are useful pointers. Surgical resection is advised as malignant transformation may occur.

Myxomatous tumours of the liver are evidently very rare, but may be responsible for a painful mass $^{70}$ : the single reported case was probably benign. Benign cystic hepatoblastoma occurs in preschool children, ${ }^{71}$ usually presenting as an abdominal mass with multiocular cysts on investigation; transformation to cystadenocarcinoma may occur if unresected. Malignant cystic hepatoblastoma is a distinct and very rare paediatric tumour where the malignant component of the tumour is stromal rather than epithelial,,$^{70}$ the prognosis is poor.

Cystic metastases from carcinoma of the ovary and kidney, and from intra-abdominal sarcomas are also described. The malignant nature of these lesions is usually apparent from associated parenchymal disease, or from the classical sonographic appearance of a malignant cyst, with thick irregular walls studded by nodules. ${ }^{12}$ The diagnosis will usually be clarified by aspiration cytology, but serial scanning is almost as helpful as cystic metastases typically enlarge rapidly.

\section{OTHER CYSTIC DISORDERS}

Various other cystic disorders have been described, of which 'ectopic' pancreatic pseudocyst is perhaps the most common, but accurate diagnosis is otherwise unusual without histological examination of material obtained at surgery or autopsy. Any list is unlikely to be comprehensive.

Occlusion of small portal vein branches from any cause (particularly compression by adjacent hepatic tumour) can produce areas of apparent infarction manifest as small cystic areas; as tissue necrosis is absent these are now generally known as pseudoinfarcts of $\mathrm{Zahn}^{72}$ and have no prognostic significance in their own right.

Peliosis hepatis was originally described in the terminal cachexia of disseminated tuberculosis, but is now most often seen in women on combined contraceptive pill. Work from this unit clarified a link between peliosis and long term androgen therapy, ${ }^{73}$ and associations with other conditions such as HIV infection are also recognised.$^{74}$ It is probably underdiagnosed as investigation is embarked upon only in those who develop hepatomegaly or abnormalities of liver function. Histologically there are blood filled cavernous cysts in continuity with the sinusoids. Cysts vary in size but may reach $5 \mathrm{~mm}$ in diameter and allow sonographic recognition. Peliosis is usually harmless, and it will often regress if a predisposing factor can be withdrawn. Rarely, liver failure or hepatic rupture may occur. Sinusoidal ectasia appears to be a milder form of peliosis and may represent its earliest manifestations.

Less than 20 cases of ciliated hepatic foregut cyst have been described. ${ }^{75}$ They are thought analogous to bronchogenic cysts, with which they share a ciliated mucus secreting pseudostratified columnocuboidal lining with a muscular wall and surrounding fibrous tissue. Characteristically they have a subcapsular site and are usually less than $3 \mathrm{~cm}$ in diameter. The sonographic findings include heterogeneous echogenic semi fluid contents (which may at first sight appear solid) within a well demarcated lesion, and aspiration reveals viscous mucinous exudative fluid. They are non-neoplastic and require no treatment if the diagnosis is certain.

Endometriosis may also be responsible for hepatic cysts, successfully treated in the first report $^{76}$ by resection. Had the diagnosis been realised preoperatively might hormonal therapy have sufficed?

Post traumatic hepatic cysts are recognised ${ }^{2}$ in addition to the cystic spaces that may remain after successful non-drainage treatment for liver abscess. A similar phenomenon has been reported from the Liver Unit after apparently curative hepatic artery embolisation (for metastatic apudoma), ${ }^{77}$ and is probably not uncommon after this intervention.

Cystic fibrosis is not, it appears, associated with higher frequencies of hepatobiliary cysts than would be expected by chance.

\section{Conclusion}

There is much in the collected literature on hepatic and biliary cystic disorders to suggest common threads in aetiology, pathogenesis, clinical presentation, complications and management (assuming that cysts of infective or neoplastic origin are excluded). The strong association of adult polycystic kidney disease with polycystic liver disease is not complete, and it need not be assumed that the hepatic cysts are encoded for by the same gene defect. The various overlap syndromes earlier alluded to allow the possibility that even if polycystic liver disease is also of autosomal dominant inheritance, it has variable expression with relatively low penetrance. Almost all hepatobiliary cysts are lined 
by biliary epithelium or epithelium with strong biliary characteristics. All most probably develop in the prenatal period (and clinical presentation is generally commoner in childhood). All are more common in women and there are suggestions that hormonal factors may be relevant. All share an assocation with hepatic fibrosis, although the strength of the association admittedly varies according to the major characteristics of the cystic disorder. Most, and probably all, of the cysts engender a substantially increased risk of biliary tract malignancy (and perhaps hepatic neoplasia also), the added risk appearing to be greatest where the cyst is in communication with the bilary tree. It is unusual for cysts themselves to be responsible for symptoms, but the complications, including those of portal hypertension, that lead to presentation are common to all varieties. Management can usually afford to be expectant except for choledochal cysts where, because of the cancer risk, elective resection is indicated. There seems every reason to support and extend the belief ${ }^{78}$ that there is a family of interlocked and overlapping hepatobiliary fibrocystic disorders - a view held in part for many years on the Liver Unit. ${ }^{79}$

1 Wilson MA, Ruzicka FF, eds. Modern imaging of the liver. New York: Marcel Dekker, 1989.

2 Gaines PA, Sampson MA. Prevalence and characterization of simple hepatic cysts by ultrasound examination. $\mathrm{Br} \mathcal{F}$ Radiol 1989; 62: 335-7.

3 Wilcox DM, Weinreb JC, Lesh P. MR imaging of a hemorrhagic hepatic cyst in a patient with polycystic liver disease. f Comput Assist Tomogr 1985; 9: 183-5.

4 Wittenberg J, Stark DD, Forman BH, et al. Differentiation of hepatic metastases from hepatic hemangiomas and cysts by using MR imaging. Am $\mathcal{F}$ Roentgenol 1988; 151: 79-84.

5 McCorkell SJ. Unintended percutaneous aspiration of pulmonary echinococcal cysts. Am $\mathcal{J}$ Roentgenol 1984; 143: 123-6.

6 Mueller PR, Dawson SL, Ferrucci TJ Jr, Nardi GL. Hepatic echinococcal cyst: successful percutaneous drainage. Radiology 1985; 155: 627-8.

7 Filice C, Pirola F, Brunetti E, Dugheti S, Strosselli M, Foglieni CS. A new therapeutic approach for hydatid liver cysts: aspiration and alcohol injection under sonographic guidance. Gastroenterology 1990; 98: 1366-8.

8 Murphy BJ, Casillas J, Ros PR, Morillo G, Albores-Saavedra J, Rolfes DB. CT appearance of cystic masses of the liver. Radiographics 1989; 9: 307-22.

9 Williamson RCN, Ramus NI, Shorey BZ. Congenital solitary cysts of the liver and spleen. Br $\mathcal{F}$ Surg 1978; 65: 871-6.
che

10 Pinto MM, Kaye AD. Fine needle aspiration of cystic liver lesions. Cytological examination and carcinoembryonic antigen assay of cyst contents. Acta Cytol 1989; 33: 852-6.

11 Roisman I, Barak V, Fields S, Bloom R, Okon E, Manny J, Solitary non-parasitic cyst of the liver: a rare cause of abdominal distension. Am f Gastroenterol 1989; 84: 1095-9.
Clinkscales NB, Trigg LP, Poklepovic J. Obstructive jaundice secondary to benign hepatic cyst. Radiology 1985; 154: 643-4.

13 Ayyash K, Haddad J. Spontaneous rupture of a solitary nonparasitic cyst of the liver. Acta Chir Scand 1988; 154: 241-3.

14 Rashed A, May RE, Williamson RCN. The management of large congenital liver cysts. Postgrad Med $\mathcal{F}$ 1982; 58: 536-41.

15 Lotz GW, Stahlschmidt M. Intra-abdominal bleeding after rupture of hepatic cyst. South Med F 1989; 82: 667.

16 Akriviadis EA, Steindel H, Ralls P, Redeker AG. Spontaneous rupture of nonparasitic cyst of the liver. Gastroenterology 1989; 97: 213-5.

17 Chang D. Solitary non-parasitic liver cyst treated by cystgastrostomy. Postgrad Med f 1988; 64: 459-61.

18 Trinkl W, Sassaris M, Hunter FM. Nonsurgical treatment of symptomatic nonparasitic liver cyst. Am $\mathcal{f}$ Gastroenterol 1985; 80: 907-11.

19 Tsuboi Y, Yamada H, Arai T, et al. Treatment of large hepatic cyst by absolute ethanol injection into the cavity. fikeika Med F 1987; 34: 583-92.

20 Huguier M, Paquet JC, Roland J, Houry S, Lacaine F. Biliary cysts of the liver. Dig Surg 1990; 7:93-6.

21 Hayashi I, Tomoda $H$, Tanimoto $M$, et al. Mucoepidermoid carcinoma arising from a preexisting cyst of the liver. $\mathcal{F}$ Surg Carcinoma arising from

22 Rehulova E, Dite P. Multifocal carcinoma arising from a congenital cyst of the liver and the kidneys. Cesk Patol 1981; 17: 198-203

23 Lynch MJ, McLeod MK, Weatherbee L, Gilsdorf JR, Guice KS, Eckhauser FE. Squamous cell cancer of the liver arising from a solitary benign nonparasitic hepatic cyst. Am 7 Gastroenterol 1988; 83: 426-31.

24 Devine P, Ucci AA. Biliary cystadenocarcinoma arising in a congenital cyst. Hum Pathol 1985; 16: 92-4.

25 Karhunen PJ, Pentrilä A, Liesto K, Männikkö A, Möttönen $M$. Benign bile duct tumours, non-parasitic liver cysts and liver damage in males. $\mathcal{F}$ Hepatol 1986; 2: 89-99.

26 Grünfeld J-P, Albouze $G$, Jungers $P$, et al. Liver changes and complications in adult polycystic kidney disease. Adv Nephrol 1985; 14: 1-20.

27 Dalgaard OZ. Bilateral polycystic disease of the kidneys: a follow-up of 284 patients and their families. Acta Med Scand (suppl) 1957; 328: 1-255.

28 Gabow PA, Johnson AM, Kaehny WD, Manco-Johnson ML Duley IT, Everson GT. Risk factors for the development of hepatic cysts in autosomal dominant polycystic kidney disease. Hepatology 1990; 11: 1033-7.

29 Everson GT, Emmett M, Brown WR, Redmond P, Thickman D. Functional similarities of hepatic cysts and biliary epithelium: studies of fluid constituents and in vivo secretion in response to secretin. Hepatology 1990; 11: 557-65.

30 Moschowitz E. Non-parasitic cysts (congenital) of the liver, with a study of aberrant bile ducts. Am $\Im$ Med Sci 1906; 131: 674-99.

31 Van Erpecum KJ, Janssens AR, Terpstra JL, Tjon-A-Tham RTO. Highly symptomatic adult polycystic disease of the liver: a report of 15 cases. $\mathcal{F}$ Hepatol 1987; 5: 109-17.

32 Cobben JM, Breuning MH, Schoots C, Kate LPT, Zerres K. Congenital hepatic fibrosis in autosomal-dominant polycystic kidney disease. Kidney Int 1990; 38: 880-5.

33 Telenti A, Torres VE, Gross JB Jr, Van Scoy RE, Brown ML, Hattery RR. Hepatic cyst infection in autosomal dominant polycystic kidney disease. Mayo Clin Proc 1990; 65: 933-42.

34 Ratcliffe PJ, Reeders S, Theaker JM. Bleeding oesophagea varices and hepatic dysfunction in adult polycystic kidney varices and hepatic dysfunction
disease. $B M \mathcal{F} 1984 ; 288$ : $1330-1$.

35 Starzl TE, Reyes J, Tzakis A, Mieles L, Todo S, Gordon R. Liver transplantation of polycystic liver disease. Arch Surg 1990; 125: 575-7

36 Murray-Lyon IM, Shilkin KB, Laws JW, Illing RC, Williams $R$. Non-obstructive dilatation of the intrahepatic biliary tree with cholangitis. Q f Med 1972; XLI: 477-89.

37 De Vos M, Barbier F, Cuvelier C. Congenital hepatic fibrosis. f Hepatol 1988; 6: 222-8.

38 Tazelaar HD, Payne JA, Patel NS. Congenital hepatic fibrosis and asymptomatic familial adult-type polycystic kidney disease in a 19-year-old woman. Gastroenterology 1984; 86: 757-60.

39 Caroli J, Soupault R, Kossakowski J, et al. La dilatation polykystique congenitale des voies biliaires intrahépatiques. polykystique congenitale des voies biliaires intrahepatiques

40 Hoglund M, Muren C, Schmidt D. Caroli's disease in two sisters: diagnosis by ultrasonography and computed tomography. Acta Radiol 1989; 30: 459-62.

41 Borda F, Uribarrena R, Puras A, Ortiz H, Rivero-Puente A Resection hépatique pour maladie de Caroli limitée au lobe gauche. Gastroenterol Clin Biol 1982; 6: 511-2.

42 Mercardier M, Chigot JP, Clot JP, Langlois P, Lansiaux P. Caroli's disease. World f Surg 1984; 8: 22-9.

43 Aeberhard P. Surgical management of Caroli's disease involving both lobes of the liver. Brf Surg 1985; 72: 651-2.

44 Barker EM, Kallideen JM. Caroli's disease: successful management using permanent-access hepaticojejunostomy. BrF Surg 1985; 72: 641-3.

45 Boyle MJ, Doyle GD, McNulty JG. Monolobar Caroli's disease. Am $\mathcal{F}$ Gastroenterol 1989; 84: 1437-44.

46 Chaimoff C, Lurie B, Gal R. Budd-Chiari-like syndrome in Caroli's disease. $\mathcal{F}$ Clin Gastroenterol 1986; 8: 586-8.

47 Rogstad K, Freeman J, Moorghen M, Record CO. Difficulty in diagnosing complications of Caroli's disease. $\mathrm{f}$ Clin Gastroenterol 1986; 8: 582-5.

48 Genève J, Dubuc N, Mathieu D, Zafrani ES, Dhumeaux D, Métreau J-M. Cystic dilatation of intrahepatic bile ducts in primary sclerosing cholangitis. F Hepatol 1990; 11: 196-9.

49 Jordon D, Harpaz N, Thung SN. Caroli's disease and adul polycystic kidney disease: a rarely recognised association. Liver 1989; 9: 30-5.

50 Fozard JBJ, Wyatt JI, Hall RI. Epithelial dysplasia in Caroli's disease. Gut 1989; 30: 1150-3.

51 Saxena R, Pradeep R, Chander J, et al. Benign disease of the common bile duct. Br $\mathcal{F}$ Surg 1988; 75: 803-6.

52 Yamaguchi M. Congenital choledochal cyst. Analysis of 1433 patients in the Japanese literature. Am $\mathcal{F}$ Surg 1980; 140 653-7.

53 Alonso-Lej F, Rever WB, Pessagno DJ. Congenital choledochal cyst, with a report of 2 , and an analysis of 94 , cases. Int Abstr Surg 1959; 108: 1-30.

54 Tandon RK, Grewal H, Anand AC, Vashisht S. Caroli's syndrome: a heterogeneous entity. Am $\mathcal{f}$ Gastroenterol 1990 85: $170-3$.

55 Olbourne NA. Choledochal cysts - a review of the cystic anomalies of the biliary tree. Ann R Coll Surg Engl 1975; 56: 26-32.

56 Vanderpool D, Lane BW, Winter JW, Ettinger J. Choledochal cysts. Surg Gynecol Obstet 1988; 167: 447-51.

57 Wiedmeyer D, Stewart ET, Dodds WJ, Geenen JE, Vennes JA, Taylor AJ. Choledochal cyst: findings on cholangiopancreatography with emphasis on ectasia of the common pancreatography with emphasis on ectasia of
channel. Am $\mathcal{F}$ Roentgenol 1989; 153: 969-72.

58 Forbes A, Leung JWC, Cotton PB. Relapsing acute and chronic pancreatitis. Arch Dis Child 1984; 59: 927-34.

59 Todani T, Urushihara N, Watanabe Y, et al. Pseudopancreatitis in choledochal cyst in children: intraoperative study of amylase levels in the serum. I Pediatr Surg 1990; 25: $303-6$. 
60 Iwafuchi M, Ohsawa Y, Naito M, Maruta Y, Saito H. Familial occurrence of congenital bile duct dilatation. $\mathcal{F}$ Pediatr Surg 1990; 25: 353-55.

61 Tan KC, Howard ER. Choledochal cyst: a 14 year surgical experience with 30 patients. Br F Surg 1988; 75: 892-5.

62 Todani T, Watanabe Y, Toki A, Urushihara N, Sato Y. Reoperation for congenital choledochal cyst. Ann Surg 1988; 207: 142-7.

63 Joseph VT. Surgical techniques and long-term results in the treatment of choledochal cyst. $\mathcal{F}$ Pediatr Surg 1990; 25: $782-7$.

64 Saing H, Tam PKH, Lee JMH, Pe-Nyun. Surgical management of choledochal cysts: a review of 60 cases. $\mathcal{F}$ Pediat Surg 1985; 20: 443-8.

65 Flanigan DP. Biliary carcinoma associated with biliary cysts. Cancer 1977; 40: 880-3.

66 Todani T, Watanabe Y, Toki A, Urushihara N. Carcinoma related to choledochal cysts with internal drainage operations. Surg Gynecol Obstet 1987; 164: 61-4.

67 Reveille RM, Van Stiegmann G, Everson GT. Increased secondary bile acids in a choledochal cyst: possible role in biliary metaplasia and carcinoma. Gastroenterology 1990; 99: 525-7.

68 Yoshida H, Itai Y, Minami M, Kokubo T, Ohtomo K, Kuroda A. Biliary malignancies occurring in choledochal cysts. Radiology 1989; 173: 389-92.

69 Marsh JL, Dahms B, Longmire WP Jr. Cystadenoma and cystadenocarcinoma of the biliary system. Arch Surg 1974; 109: 41-3.

70 Edmondson HA. Tumors of the liver and intrahepatic bile ducts. Atlas of tumor pathology, section VII, fascicle 23. Washington DC: Armed Forces Institute of Pathology, 1974.
71 Landing BH. Tumors of the liver in childhood. In: Okuda K, Peters RL, eds. Hepatocellular Carcinoma. New York: Wiley Medical, 1976.

72 Holdstock G, Millward-Sadler GH, Wright R. Hepatic changes in systemic disease. In: Wright $\mathbf{R}$, Millward-Sadler GH, Alberti KGMM, Karran S, eds. Liver and biliary disease, London: Baillière Tindall, 1985.

73 Paradinas FJ, Bull TB, Westaby D, Murray-Lyon IM. Hyperblasia and prolapse of hepatocytes into hepatic veins during longterm methyltestosterone therapy: possible during longterm methyltestosterone therapy: possible hepatitis and liver tumours. Histopathology 1977; 1: 225-46.

74 Perkocha LA, Geaghan SM, Yen BTS, et al. Clinical and pathological features of bacillary peliosis hepatis in association with human immuno deficiency virus infection. NEngl F Med 1990; 323: 1581-6.

75 Kadoya M, Matsui O, Nakanuma Y, et al. Ciliated hepatic foregut cyst: radiologic features. Radiology 1990; 175: 475-7.

76 Finkel L, Marchevsky A, Cohen B. Endometrial cyst of the liver. Am $\mathcal{F}$ Gastroenterol 1986; 81: 576-8.

77 Lee S-M, Forbes A, Williams R. Metastatic islet cell tumour secreting insulin and glucagon: successful treatment by hepatic artery embolization and chemotherapy. Eur f Surg Oncol 1988; 14: 265-8.

78 Summerfield JA, Nagafuchi Y, Sherlock S, Cadafalch J, Scheuer PJ. Hepatobiliary fibropolycystic diseases: a clinical and histological review of 51 patients. $\mathcal{F}$ Hepatol 1986; 2: 141-56.

79 Murray-Lyon IM, Ockenden BG, Williams R. Congenital hepatic fibrosis - is it a single clinical entity? Gastroenterology 1973; 64: 653-6. 